\title{
An environmental impact comparison of single-use and reusable thermally controlled shipping containers
}

\author{
Kai N. Goellner • Eph Sparrow
}

Received: 28 March 2013 / Accepted: 28 October 2013 /Published online: 26 November 2013

(C) The Author(s) 2013. This article is published with open access at Springerlink.com

\begin{abstract}
Purpose Pharmaceutical and biological materials require thermally controlled environments when being transported between manufacturers, clinics, and hospitals. It is the purpose of this report to compare the life cycle impacts of two distinct logistical approaches to packaging commonly used in cold chain logistics and to identify the method of least environmental burden. The approaches of interest are single-use packaging utilizing containers insulated with either polyurethane or polystyrene and reusable packaging utilizing containers with vacuum-insulated panels.

Methods This study has taken a cradle-to-grave perspective, which covers material extraction, manufacture, assembly, usage, transportation, and end-of-life realities. The functional unit of comparison is a 2-year clinical trial consisting of 30,000 individual package shipments able to maintain roughly $12 \mathrm{~L}$ of payload at a controlled $2-8^{\circ} \mathrm{C}$ temperature range for approximately $96 \mathrm{~h}$. Published life-cycle inventory data were used for process and material emissions. A populationcentered averaging method was used to estimate transportation distances to and from clinical sites during container use. Environmental impacts of the study include global warming potential, eutrophication potential, acidification potential, photochemical oxidation potential, human toxicity potential, and postconsumer waste.

Results and discussion The average single-use approach emits 1,122 tonnes of $\mathrm{CO}_{2} \mathrm{e}$ compared with 241 tonnes with
\end{abstract}

Responsible editor: Hans-Jürgen Garvens

Electronic supplementary material The online version of this article (doi:10.1007/s11367-013-0668-z) contains supplementary material, which is available to authorized users.

K. N. Goellner $(\bowtie) \cdot$ E. Sparrow

University of Minnesota, 111 Church Street SE, Minneapolis,

MN 55455, USA

e-mail: goel1003@umn.edu the reusable approach over the functional unit. This is roughly a $75 \%$ difference in global warming potential between the two approaches. Similar differences exist in other impact categories with the reusable approach showing $60 \%$ less acidification potential, $65 \%$ less eutrophication potential, $85 \%$ less photochemical ozone potential, $85 \%$ less human toxicity potential, and $95 \%$ less postconsumer waste. The cradle-to-gate emissions of the single-use container were the overwhelming cause of its high environmental burden as 30,000 units were required to satisfy the functional unit rather than 772 for the reusable approach. The reusable container was about half the mass of the average single-use container, which lowered its transportation emissions below the singleuse approach despite an extra leg of travel.

Conclusions The reusable logistical approach has shown to impose a significantly smaller environmental burden in all impact categories of interest. A sensitivity analysis has shown some leeway in the degree of the environmental advantage of the reusable approach, but it confirms the conclusion as no case proved otherwise.

Keywords Clinical trial · Cold chain · Life-cycle analysis . Logistics · Packaging · Vacuum-insulated panel · Phase change media

\section{Introduction}

The demand for thermally controlled logistics is growing in response to emerging pharmaceutical and biological markets serving an aging population. These critical activities invariably require transport between many geographically separated locations. A thermally controlled environment is required during transport in order to maintain the physical and chemical viability of the payload. This situation necessitates innovative packaging and transportation means, which contribute 
to the environmental footprint of these segments of the healthcare market. It is the goal of this research to identify current packaging options that limit this environmental impact.

There are two commonly accepted logistical approaches for the conveyance of biological and pharmaceutical payloads, each defined by its longevity of use, insulation type, and thermal management means. The most common conveyance packaging is single-use containers, implemented by the utilization of either extruded polystyrene (EPS) or polyurethane (PUR) insulation and gel pack heat sinks. The second method of interest here is a growing utilization of durable reusable containers, based on vacuum-insulated-panel (VIP) insulation and phase-change-media-based (PCM) heat sinks. The reusable container of interest in this analysis is the Credo Cube ${ }^{\circledR}$ 4-1296 produced by Minnesota Thermal Science. There have been a variety of packaging life-cycle analysis (LCA) comparison studies that focus on payload sizes and encasing materials such as the assessment of coffee packaging in Italy (De Monte et al. 2005) and carbonated beverage packaging in the UK (Amienyo et al. 2013). Others have focused exclusively on encasing materials such as the comparison between packaging options for mail-order soft goods (Franklin Associates 2004). There has been no publically available LCA study to this date concerning thermal performance packaging used in cold-chain logistics.

\section{Scope}

This analysis focuses on a 2-year time span, a period that covers half of a typical phase III pharmaceutical clinical trial (Abrantes-Metz et al. 2004). During such a period, thousands of shipments to various clinical sites around the country are expected to occur. Although the present research is focused specifically on the pharmaceutical market, it is expected that the comparative assessment will apply to similar high-volume markets in the cold-chain industry. Understanding the environmental implications of packaging decisions will help organizations meet their sustainability goals.

The functional unit used to compare the two logistical approaches of this study is a 2-year clinical trial requiring 30,000 cold-chain shipments, using containers qualified to transport $12 \mathrm{~L}$ of product maintained at temperatures of $2-8{ }^{\circ} \mathrm{C}$ for a duration of approximately $96 \mathrm{~h}$. Although these conditions cover a small portion of the totality of cold-chain scenarios, they are typical of the individual payloads conveyed in clinical trials. The stand-alone performance of containers for transporting pharmaceutical and biological payloads are qualified through laboratory testing to International Safe Transit Association procedure 7D and ASTM D3103 standards. The materials comprising the payload as well as any logistical overhead (e.g., warehouse lighting) were excluded from the system boundary. The system boundary for each logistical approach can be seen in the Electronic Supplementary Material.

Global warming potential (GWP), eutrophication potential (EP), acidification potential (AP), photochemical oxidation potential (PCOP), human toxicity potential (HTP), and postconsumer solid waste are the environmental impacts to be addressed and quantified here. Life-cycle inventory (LCI) data were converted into the aforementioned environmental indicators utilizing potential values collected from three sources: PAS2050 (British Standards Institution 2011), IPCC's Climate Change 2007: the physical science basis (Solomon et al. 2007), and an online compendium by Summerscales (2006) based on the work by Azapagic (2004).

\section{Methods}

A cradle-to-grave LCA approach has been aligned with the methodology standardized in ISO 14044 (2006) and PAS2050. The breakdown of component materials and respective mass for each logistical approach is set forth in Tables 1 and $\mathbf{2}$.

The analysis of each of the selected logistical approaches was subdivided by stages of impact occurrence as seen in Fig. 1.

The functional unit displays some of the critical assumptions of analysis. Further assumptions include:

- All clinical trial sites reside in the contiguous US

- Pharmaceutical production originates in Indianapolis, Indiana

- The reusable container ships two times per month

- Reusable container inventory sustains losses of $10 \%$ per year; combined with the foregoing assumption, this results in 772 containers needed over the 2-year clinical trial

- The polypropylene corrugate component of the reusable container is replaced every quarter

- Shipping distances between suppliers are assumed to be $1,000 \mathrm{~km}$ when no primary data are available, assuming a regional and national supply chain

Table 1 Component makeup per single-use container

\begin{tabular}{lll}
\hline Component & Mass $(\mathrm{kg})$ & Material(s) \\
\hline Insulation $^{\mathrm{a}}$ & $4.84 / 6.06$ & PUR/EPS \\
Gel packs & 8.92 & Water, CMC, LDPE \\
Gel bricks & 2.95 & Water, phenolic foam, LDPE \\
Corrugate & 1.14 & Cardboard \\
Total & $17.85 / 19.07$ & PUR model/EPS model
\end{tabular}

${ }^{a}$ Equivalent performance insulation, two materials analyzed independently 
Table 2 Component makeup per reusable container

\begin{tabular}{lll}
\hline Component & Mass $(\mathrm{kg})$ & Material(s) \\
\hline Vacuum-insulated panels & 2.90 & $\begin{array}{c}\text { Carbon silica, carbon black, } \\
\text { metalized PET film, } \\
\text { LLDPE film, PVC film, }\end{array}$ \\
PU adhesive \\
Thermal isolation chamber & 1.70 & HDPE \\
Phase change media & 3.87 & Paraffin wax blend \\
Outer corrugate & 0.93 & Polypropylene (PP) \\
Tape & 0.09 & Polypropylene (PP) \\
Total & 9.49 & \\
\hline
\end{tabular}

- When no primary data are available, $3 \%$ product loss during manufacturing is assumed.

Materials, manufacturing, and assembly data for the reusable packaging approach were obtained mainly from primary sources of a single producer. Data from several single-use packaging options on the market were averaged in order to estimate material requirements for a typical single-use container. For the latter, some emission sources may not have been captured in the same detail as for the reusable approach due to limited access.

Emissions involving raw material extraction were included in a majority of the published LCA studies from which data were collected. In cases where it was not included, emissions were determined separately and added into the respective LCI. Coproduct breakdowns and refining data of crude oil were obtained from the NREL US Life-Cycle Inventory Database (2012). A complete list of LCI data sources can be seen in Table 3. The impacts of high volume polymers (EPS and PUR) were calculated using European data. The European data were taken as a valid estimate of US emissions based on the cross-referencing of other polymer impacts [high density polyethylene (HDPE), linear low density polyethylene, polyethylene terephthalate, polyvinyl chloride, and polypropylene (PP)], which showed differences limited to 5-15\%. Considerable effort was placed in obtaining the most applicable publicly available data. The resulting impacts per kilogram of each material can be seen in Table 4.

A $2 \%$ cutoff rule by mass was used to determine which components could safely be disregarded in the analysis. Under this rule, the omitted manufacturing emissions include ethyl acetate $(0.06 \%)$, PU resin $(0.16 \%)$, aluminum $(0.01 \%)$, and manufacturing phenolic foam from phenolic resin $(1.44 \%)$. Only the $\mathrm{CO}_{2} \mathrm{e}$ emissions from the manufacturing of carboxymethyl cellulose (CMC) were accounted for due to the inaccessibility of more detailed data.

Averaged losses occurring during the assembly process were accounted for. The assembly energy required to fill and
Fig. 1 Life-cycle breakdown of differing logistical approaches

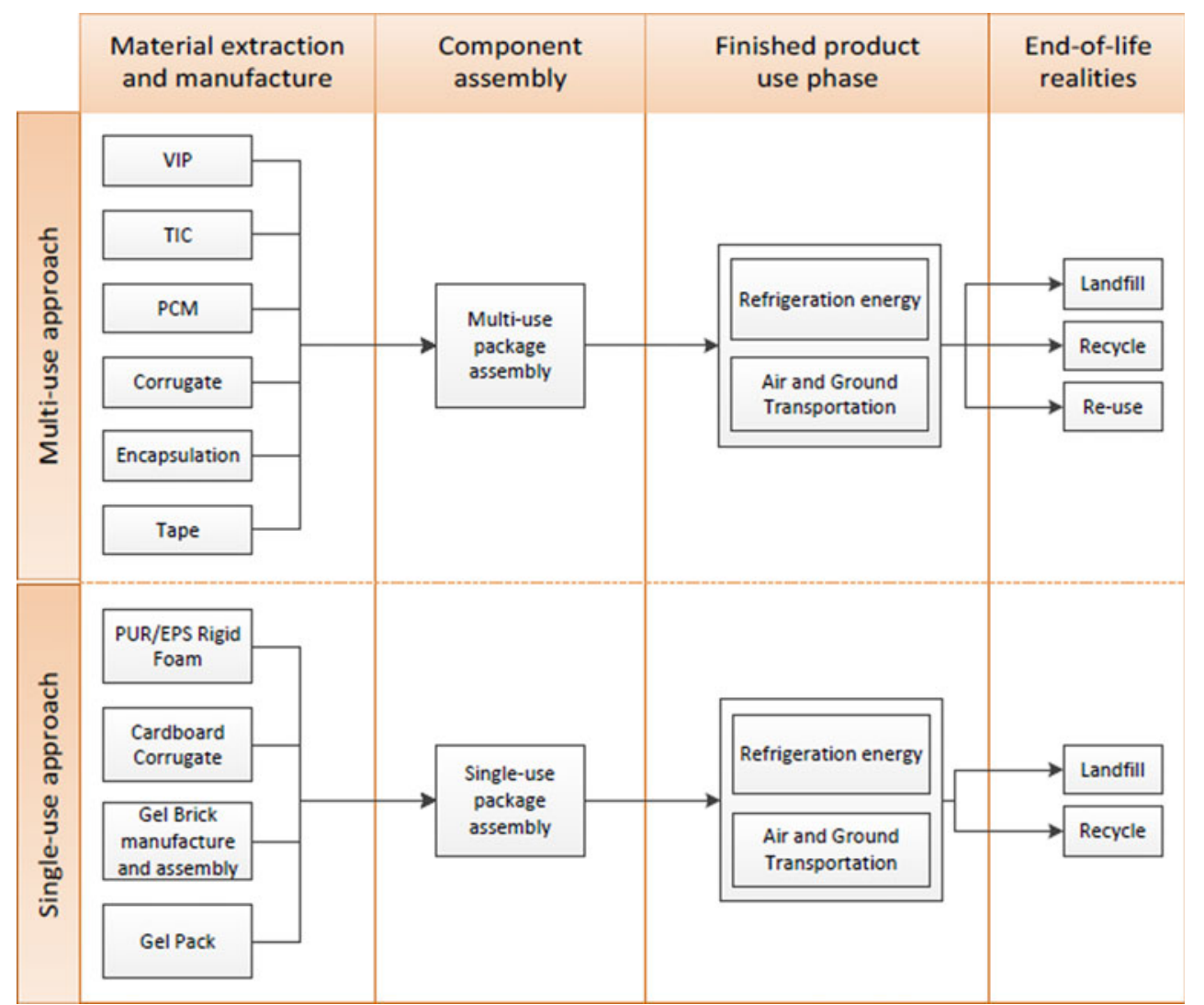


Table 3 LCI data sources

\begin{tabular}{|c|c|}
\hline Component & Data source \\
\hline $\begin{array}{l}\text { Polymer components (LLDPE, } \\
\text { PET, PUR, HDPE, PP, PVC, } \\
\text { EPS, phenol) }\end{array}$ & $\begin{array}{l}\text { Franklin Associates (Franklin } \\
\text { 2011);Boustead (2005b, 2006) } \\
\text { Plastic Europe's Eco-profiles } \\
\quad(2008,2010)\end{array}$ \\
\hline $\begin{array}{l}\text { Multilayered polymer processing } \\
\text { energy }\end{array}$ & Dimenna (2008) \\
\hline Paraffin & Tufvesson and Börjesson (2008) \\
\hline Silica and carbon black & European Commission (2007) \\
\hline Silica extraction & IMA-Europe (2007) \\
\hline Cardboard corrugate & PE Americas (2009) \\
\hline Tap water processing and treatment & Franklin Associates (2009) \\
\hline Electricity production & $\begin{array}{l}\text { US EPA eGRID database } \\
\text { (2012b); IMEP (2008) }\end{array}$ \\
\hline Crude oil extraction & Boustead (2005a) \\
\hline Carboxymethyl cellulose (CMC) & $\begin{array}{l}\text { Eco-costs for carboxymethyl } \\
\text { cellulose }(2012)\end{array}$ \\
\hline Transportation emissions & $\begin{array}{l}\text { NREL (2012), UPS (2012), FedEx } \\
\quad \text { (2012) }\end{array}$ \\
\hline Polypropylene recycling & Adams et al. (1999) \\
\hline
\end{tabular}

seal the gel packs and bricks utilized in the single-use container was omitted due to lack of data.

In many cases, transportation steps that occur during the manufacture of specific components were included in published LCI data. The contribution of this transportation to the overall environmental impact of these materials was generally in the range of $1-3 \%$. In cases where transportation steps were not accounted for in the literature, subsequent transportation emissions were included.

\subsection{Use phase}

Both the gel packs and PCM must be frozen prior to use in clinical shipments to ensure a functional heat sink. A COP of commercial refrigerators of 3.8 was used for energy conversion calculations (International Institute of Refrigeration 2002). Experimental data of the energy required to freeze the PCM was utilized. Energy required to freeze the gel packs and bricks utilized in single-use containers was estimated using the thermodynamic properties of water (freezing from a $22{ }^{\circ} \mathrm{C}$ liquid to a $0{ }^{\circ} \mathrm{C}$ solid). The mass of water to be frozen was taken as the mass of all the gel materials. It has thus been assumed that $0.12 \mathrm{kWh} / \mathrm{kg}$ is required to freeze the bricks and gel packs and $0.08 \mathrm{kWh} / \mathrm{kg}$ is required to freeze the PCM.

Four types of trucking vehicles were used in transportation emissions modeling: (a) long-haul single unit truck, (b) shorthaul single unit truck, (c) light commercial vehicle, and (d) long-haul combination truck. Vehicle types were selected depending on distance travelled and cargo tonnage based upon definitions provided by EPA MOVE documentation (2012c). $\mathrm{CO}_{2}$ and $\mathrm{NO}_{x}$ emissions were adjusted for the light commercial vehicle to account for higher efficiency UPS and FedEx fleets using carrier performance rankings as compiled by the EPA (2012a).
Table 4 LCI results per material (potential units are in $\mathrm{kg}_{\text {equivelant }}$ $\mathrm{kg}_{\text {material }}$ )

\begin{tabular}{llllll}
\hline Material & $\mathrm{CO}_{2} \mathrm{e}$ & $\mathrm{SO}_{2} \mathrm{e}$ & $\mathrm{PO}_{4}{ }^{3-} \mathrm{e}$ & $\mathrm{C}_{2} \mathrm{H}_{4} \mathrm{e}$ & $\mathrm{HTP}$ \\
\hline LLDPE film & 2.22 & 0.0087 & 0.00045 & 0.0087 & 0.0031 \\
LDPE film & 2.40 & 0.0112 & 0.00065 & 0.0097 & 0.0052 \\
OPP film & 3.20 & 0.0146 & 0.00085 & 0.0124 & 0.0052 \\
PET film & 3.13 & 0.0136 & 0.00099 & 0.0138 & 0.0065 \\
PVC film & 3.10 & 0.0140 & 0.00110 & 0.0003 & 0.0166 \\
HDPE resin & 1.89 & 0.0055 & 0.00032 & 0.0057 & 0.0023 \\
PP resin & 1.86 & 0.0055 & 0.00038 & 0.0054 & 0.0027 \\
PUR foam & 4.16 & 0.0174 & 0.00111 & 0.0139 & 0.0065 \\
EPS foam & 3.29 & 0.0104 & 0.00063 & 0.0087 & 0.0039 \\
Phenolic resin & 2.19 & 0.0101 & 0.00060 & 0.0085 & 0.0036 \\
CMC & 4.21 & - & - & - & - \\
Corrugate & 1.01 & 0.0100 & 0.00082 & 0.0008 & 0.0121 \\
Paraffin wax & 0.70 & 0.0037 & 0.00017 & 0.0011 & - \\
Silica sand & 2.93 & 0.0097 & 0.00106 & 0.0012 & 0.0133 \\
Carbon black & 0.60 & 0.0545 & 0.00238 & 0.1852 & 0.0658 \\
PU adhesive & 3.30 & 0.0104 & 0.00066 & 0.1363 & 1.1239 \\
Water (extraction and transport) & 0.0003 & 0.000007 & 0.000006 & 0.0001 & - \\
\hline
\end{tabular}


Transportation was assumed to provide next-day delivery with logistical steps determined by regional location and distance from the payload origin. Distances were weighted by regional location and population distribution (US Census Bureau 2010). Transportation distances were allocated to the total 30,000 shipments based on the distribution of pharmaceutical clinical trials around the US (National Institute of Health 2012). Return shipments of the reusable package are not time critical and are assumed to be ground transported primarily in combination long-haul trucks from the clinical site back to the pharmaceutical manufacturer in Indianapolis, IN, USA.

Transportation emissions are based on vehicle emissions only. Facility utility requirements and other overhead emissions associated with logistical processes are beyond the scope of these calculations.

\subsection{End-of-life}

Nonrecycled components utilized in each packaging method are conglomerated into a "postconsumer solid waste" metric. Based on discussions with pharmaceutical providers about current practices in clinical trials, all components of the single-use container, except for the majority of the cardboard corrugate, are assumed to be landfilled. The reusable container components that are typically landfilled include PVC film and the multilayered VIP film. The cut-off recycling method has been applied in consideration of the HDPE TIC's coating process, which requires it to use all-virgin resins and makes it not readily accepted by local recyclers. Thus, any TIC recycling reduces its "postconsumer solid waste" impact category only. Transport of materials to landfills and recycling centers are assumed to be $50 \mathrm{~km}$. Refuse truck emissions data were obtained through the US Life-Cycle Inventory Database.

Both closed- and open-loop allocation techniques were used in calculating the positive effect of recycling on emissions and were employed based on the whether the recycled material is used to remake the same product, or a different product, respectively. Closed-loop impact allocations are calculated utilizing Eq. (1) as given by the PAS:2050 literature (British Standards Institution 2011),

Impact $=(1-r) E_{\mathrm{V}}+r E_{\mathrm{R}}+(1-r) E_{\mathrm{D}}$

It is assumed that $50 \%$ of recyclable products are in fact recycled for baseline calculations, where $r$ is the fraction recycled, $E_{\mathrm{V}}$ is the emissions total using all virgin raw material, $E_{\mathrm{R}}$ is the emissions total using all recycled raw material, and $E_{\mathrm{D}}$ is the emissions total arising from disposal of nonrecycled material.

PCM and VIPs are shipped back to the manufacturer by the client for recycling. There is no quality loss of the PCM or the insulating core and no material processing is required for reuse in this closed-loop system. The silica and carbon black are the only recyclable materials in the VIP component, with Eq. (1) being used accordingly.

The outer component of the reusable package is comprised of fully recyclable polypropylene. Actual end-of-life recycling fractions are unknown; however, all process scrap is recycled. The component is extruded using $100 \%$ virgin PP resin so that recycling is accounted for using an open-loop methodology. The 50/50 open-loop method for a two-product system was applied in a fashion similar to that described by Ekvall and Tillman (1997) under the assumption that a demand for recycled material is required to facilitate recycling. Half of the virgin resin production impact, eventual disposal impact, and recycling impact is allocated to the original product virgin material. The allocation procedure is shown in Eq. (2) where $r$ is the fraction recycled, $V$ is the impact from sourcing all virgin material, $D$ is the impact from disposal, and $R$ is the impact from recycling.

Impact $=r\left(\frac{V-D}{2}+\frac{R}{2}\right)+(1-r)(V+D)$

\section{Results}

The single-use approach, as seen in Figs. 2, 3, and 4, has a far greater environmental burden across all impact categories analyzed. The difference in cradle-to-gate emissions between the single-use and reusable approaches is the primary cause of the increased environmental impact of the former. The gate in this case refers to the end of the component assembly phase.

In Fig. 2, it is seen that there are $91.4 \%$ more $\mathrm{CO}_{2} \mathrm{e}$ emissions for the PUR case during this cradle-to-gate interval compared to $78.5 \%$ from cradle-to-grave. The average singleuse approach has 4.7 times higher cradle-to-grave global warming emissions than the reusable approach over the functional unit. End-of-life contributions to the overall environmental impact comprise $<1 \%$ of the overall impact, encompassing only the transportation to landfills and recyclers since recycled material benefits were discounted during the cradle-to-gate stage. Between the two single-use approaches, the PUR insulated option has a slight overall edge over the EPS option in all impact categories.

Figure 3 sets forth categories that display environmental impacts to the greater ecosystem. As with GWP, the average single-use approach has a much greater environmental burden under this broader scope of measure then does the reusable approach with $66 \%$ more AP emissions, $68 \%$ more EP emissions, $87 \%$ more PCOP emissions, and $57 \%$ more HTP emissions. Use-phase emissions make up almost entirely of transportation emissions and contribute the majority of all impact categories for the reusable packaging approach and contribute the bulk of EP and HTP emissions for the singleuse approach. The foregoing percentages correspond to an 


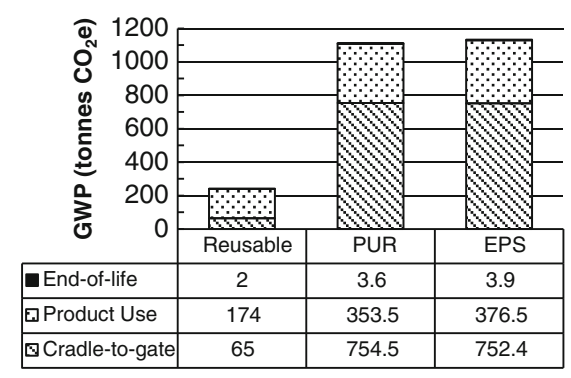

Fig. 2 Comparison of cradle-to-grave global warming potential per functional unit among the reusable, PUR single-use, and EPS single-use approaches

increased environmental burden of $3,070 \mathrm{~kg}$ more $\mathrm{SO}_{2} \mathrm{e}$, $880 \mathrm{~kg}$ more $\mathrm{PO}_{4}{ }^{3-} \mathrm{e}, 2,030 \mathrm{~kg}$ more $\mathrm{C}_{2} \mathrm{H}_{4} \mathrm{e}$, and $2,150 \mathrm{~kg}$ more toxic substances for the single-use approach compared with the reusable logistical approach over the functional unit of 30,000 shipments. The reusable approach transportation accounts for $63 \%$ of AP emissions, $90 \%$ of EP emissions, $81 \%$ of PCOP emissions, and $56 \%$ of human toxicity emissions. Emissions for the single-use approaches in these categories lower to about $44,66,24$, and $53 \%$ of their total footprints, respectively.

A comparison of postconsumer solid waste is shown in Fig. 4. There is a substantial difference between the two options. Only 7 tonnes of landfilled material is generated by the reusable approach over the functional unit versus 157 tonnes for the PUR option, and 194 tonnes for the EPS option.

\subsection{Sensitivity analysis}

There are several assumptions made in this analysis that lead to uncertainty in the accuracy of the comparisons. A sensitivity analysis with respect to these assumptions is critical in providing an unbiased view of the model prior to making conclusions. Among the factors investigated in the sensitivity analysis are mass requirements for the singleuse approach, transportation distance during the use-phase, fraction recycled, and supplier-to-supplier transportation distance assumption.

\subsubsection{Single-use component mass requirements}

All emissions arising from material production, refrigeration energy, and transportation are a linear function of mass. Table 5 shows the calculated sensitivity of each environmental indicator given $\pm 15 \%$ change in mass requirements.

From Fig. 5, it is seen that the reduction of mass by $15 \%$ gives rise to a corresponding reduction in the $\mathrm{CO}_{2} \mathrm{e}$ tonnage emission. For instance, the ratio of the baseline emissions for the single-use and reusable use situations is 4.6. In contrast, for a $15 \%$ mass reduction for the single-use case, the ratio
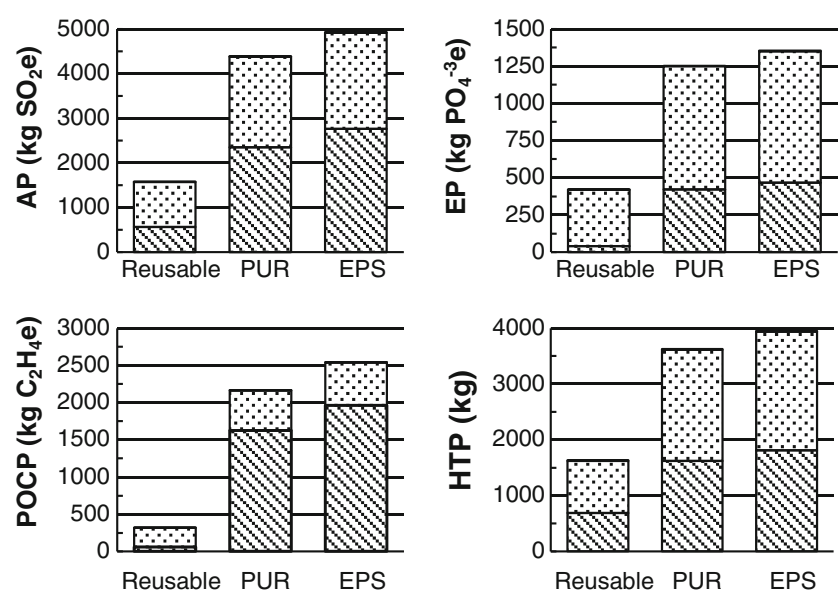

\$Cradle-to-gate OProduct Use $\square$ End-of-life

Fig. 3 Comparisons of acidification potential, eutrophication potential, photochemical ozone creation potential, and human toxicity potential per functional unit among the reusable, PUR single-use, and EPS single-use approaches

diminishes to 3.9. This reduction may result in a container whose material makeup is unable to meet the thermal qualifications necessary to fulfill the functional unit.

\subsubsection{Use-phase transportation distance}

The use-phase transportation analysis assumes average distances that may exceed or underestimate actual shipping distances. Because emissions calculations use an equally weighted function of mass and distance, a $15 \%$ change in mass results in a $15 \%$ change in the emission. It is clear that singleuse container emissions are more sensitive to the average transportation distance than are those of the reusable container due to its heavier shipping weight, which results in greater use-phase transportation emissions given the baseline case. Sensitivity to the average transportation distance is notably smaller than to material mass requirements.

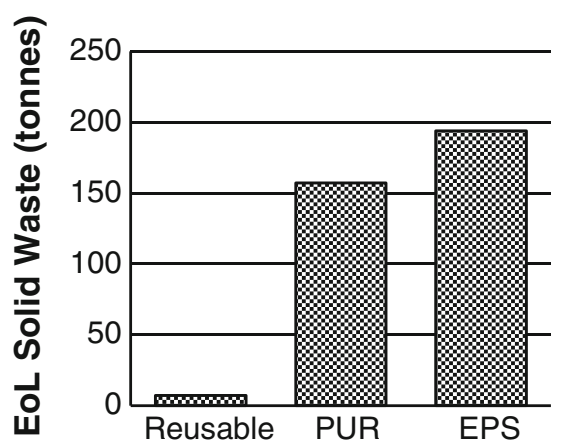

Fig. 4 Comparison of end-of-life consumer solid waste per functional unit among the reusable, PUR single-use, and EPS single-use approaches 
Table 5 Sensitivity of material mass requirement for single-use approach

\begin{tabular}{|c|c|c|c|c|c|c|}
\hline & & $\begin{array}{l}\text { GWP } \\
\text { (tonnes } \mathrm{CO}_{2} \mathrm{e} \text { ) }\end{array}$ & $\mathrm{AP}\left(\mathrm{kg} \mathrm{SO}_{2} \mathrm{e}\right)$ & $\mathrm{EP}\left(\mathrm{kg} \mathrm{PO}_{4}{ }^{3-} \mathrm{e}\right)$ & $\begin{array}{l}\mathrm{PCOP} \\
\left(\mathrm{kg} \mathrm{C}_{2} \mathrm{H}_{4} \mathrm{e}\right)\end{array}$ & $\begin{array}{l}\text { HTP } \\
(\mathrm{kg})\end{array}$ \\
\hline PUR option & $\pm 15 \%$ mass & \pm 167 & \pm 657 & \pm 188 & \pm 324 & \pm 543 \\
\hline EPS option & $\pm 15 \%$ mass & \pm 170 & \pm 739 & \pm 203 & \pm 381 & \pm 592 \\
\hline
\end{tabular}

\subsubsection{Fraction recycled}

Current component recycling fractions are unknown and may be above or below the $50 \%$ value assumed in the baseline calculation. Sensitivity of environmental impacts to recycling fraction can be seen in Fig. 6 for the extreme values of 0 and $100 \%$. It is clear that recycling has the greatest impact on the amount of postconsumer solid waste that ends up in the landfill. It is estimated that every percent increase in fraction recycled results in a reduction of $115 \mathrm{~kg}$ of postconsumer waste.

\subsubsection{Supplier-supplier transportation distance}

Transportation distances between suppliers were estimated at $1,000 \mathrm{~km}$ when unknown. This assumption generalizes regional product sourcing. This may be an underestimate if the product mix involves many international interactions or an overestimate if local interactions dominate.

Analysis has shown that the supplier-supplier assumption has little bearing on the reusable approach due to the majority supplier distances being known from primary sources. The analysis of the single-use logistical approaches, however, shows greater sensitivity to this assumption since all supplier-supplier distances are assumed at 1,000 km. Figure 7 shows the sensitivity of the PUR container to supplier-supplier distance. The greatest sensitivity is seen in the EP and HTP of the single-use approaches with average increases of 23.8 and $16.5 \%$ of the respective indicator emissions per $500 \mathrm{~km}$ increase in distance between suppliers. The bestcase scenario of complete local sourcing reduces the GWP by $8.6 \%$ from the baseline.

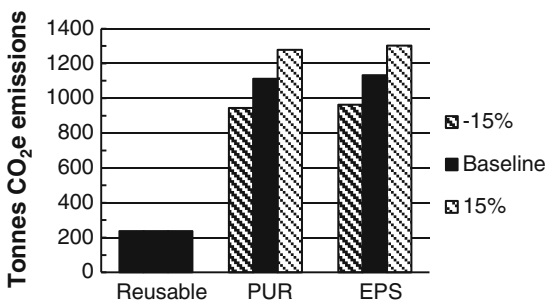

Fig. 5 Single-use material mass requirement sensitivity analysis effect on carbon footprint

\section{Discussion}

The life-cycle analysis performed in this study has identified which logistic approach to cold-chain shipments will incur the least potential impact to the environment. It has been shown that a reusable logistical approach can considerably reduce the environmental impacts of transporting thermally controlled payloads. The foremost disadvantages of the single-use logistical approach lie in the emissions generated in the cradle-togate phase, where 12 times the GWP is generated relative to the reusable approach. This considerable difference is intrinsic to the single-use approach as 30,000 new boxes must be manufactured in order to fulfill the functional unit compared to 772 for the reusable approach. Containment will always be needed to protect payloads during transportation. It is important for organizations to carefully consider the impact of their containment, packaging, and shipping decisions, especially when high volumes of transactions are involved.

Container mass has shown to be critical to transportation impacts. The reusable logistical approach requires return transportation during its use-phase, a key difference between the two approaches. Despite this increased travel per use, the reusable case had reduced use-phase transportation emissions due to the considerable differences in container mass between these logistical approaches. This difference is further compounded by the initial delivery of the containers to the distribution point from the manufacturer.

The mass was also shown to be critical when considering the differences between the two single-use insulation options. Although PUR insulation inflicts a greater environmental burden than does EPS insulation per kilogram of product during production, the increased mass of EPS required for equivalent thermal performance results in increased production and transportation emissions, making it a less desirable single-use insulation option over the product lifespan.

The single-use logistical approach will be able to lessen its impact and may be able to compete with the reusable approach by means of a robust PUR and EPS insulation recycling infrastructure. The major barrier to recycling of single-use containers is the scattering of clinical sites that do not have the local capability to recycle these materials. This may be accompanied by a perception barrier at these sites where the quantity of containers is so small as to create the view that 
Fig. 6 Sensitivity of reusable approach impacts to assumption of fraction recycled

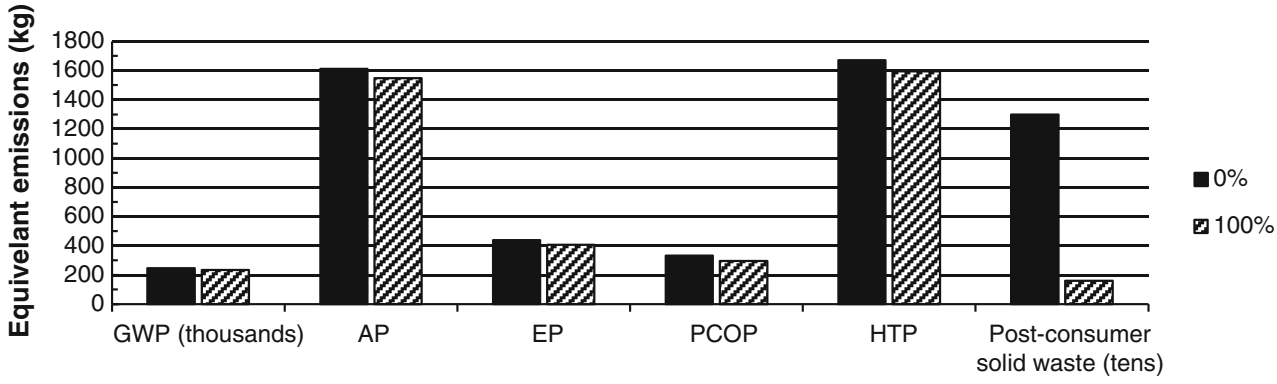

there is not much waste. These barriers do not exist in the case of recycling the reusable components because they already reside in a logistical framework that utilizes multiple instances of return shipping.

The sensitivity analysis has exposed the plasticity of the environmental impact assessment to key assumptions regarding single-use container material requirements, use-phase transportation distances, recycling fractions of the reusable approach, and supplier transportation distances. A reduction in the mass of material necessary for the single-use container has been shown to be the greatest source of reduction in the GWP of that approach. An assumed $15 \%$ mass reduction would save about 170 tonnes of GWP emissions over the functional unit. It is important to note, however, that this amount of mass reduction may not be feasible without reducing the thermal performance of the container. The magnitude of the recycling fraction for the reusable approach components had a substantial effect on the amount of postconsumer waste generated, with other impact categories moderately affected. The single-use approach is more sensitive to changes in usephase transportation distances because its container has nearly twice the mass of the reusable approach. Maximum reduction in supplier-supplier distance was shown to reduce the GWP for the single-use approach up to $8.6 \%$.

\section{Conclusions}

This LCA study has evaluated critical environmental impact differences between reusable and single-use logistical

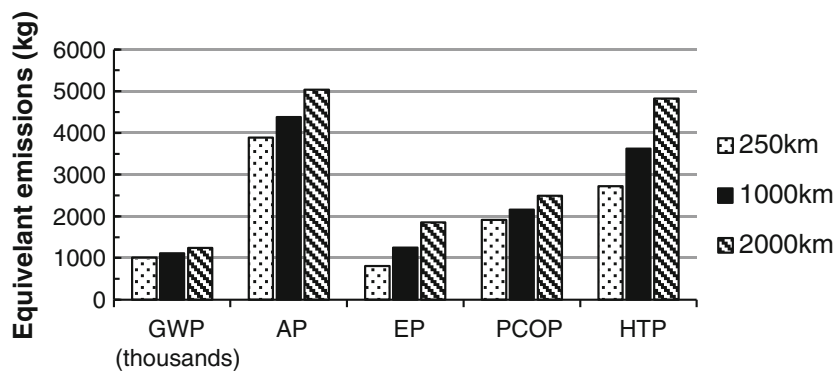

Fig. 7 Sensitivity of PUR single-use approach to supplier-supplier average distance approaches to thermally controlled containments. The reusable logistical approach utilizing VIP insulation and PCM heat sinks has substantially exceeded the environmental performance of the single-use approach in all metrics studied in this paper. It is estimated that choosing a reusable logistical approach relative to the single-use approach over a course of 30,000 shipments would reduce environmental impacts by the following percentages:

- Global warming emissions (GWP)-78 \%

- Acidification emissions (AP) $-66 \%$

- Eutrophication emissions (EP)-67\%

- Photochemical ozone emissions (PCOP)-86\%

- Human toxicity emissions (HTP) $-56 \%$

- Post-consumer waste- $95 \%$

The use of nondomestic European data adds some uncertainty to the baseline percentages; however, the expected emissions error affecting the cradle-to-gate phase is a small fraction of the differences seen in the comparison between the two logistical approaches. A sensitivity analysis has also shown a moderate uncertainty in the above percentages, but has confirmed the conclusion that the reusable approach is environmentally superior to the single-use approach.

The environmental break-even point between the two logistical approaches occurs after as few as six shipments for PCOP and as many as 17 shipments for HTP emissions. This outcome strongly suggests that a reusable approach is environmentally preferable for any organization that utilizes large shipping volumes that require thermal control.

Acknowledgments The authors would like to thank Minnesota Thermal Science for their financial support. Generous thanks are due to all the suppliers involved it the study, this research would not have been possible without their commitment and openness to data collection. We would also like to acknowledge those at NREL and PlasticsEurope for their help with LCI data and their commitment to providing a public data bank emission research.

Open Access This article is distributed under the terms of the Creative Commons Attribution License which permits any use, distribution, and reproduction in any medium, provided the original author(s) and the source are credited. 


\section{References}

Abrantes-Metz RM, Adams CP, Metz A (2004) Pharmaceutical development phases: a duration analysis. Federal Trade Commission, Washington

Adams K, Bankston J, Barlow A, Holdren MW, Meyer J, Marchesani VJ (1999) Development of emission factors for polypropylene processing. J Air Waste Manag Assoc 49(1):49-56

Amienyo D, Gujba H, Stichnothe H, Azapagic A (2013) Life cycle environmental impacts of carbonated soft drinks. Int J Life Cycle Assess 18(1):77-92

Azapagic AR (2004) Sustainable development in practice - case studies for engineers and scientists. Wiley, New York

Boustead I (2005a) Eco-profiles of the European plastics industry: crude oil. PlasticsEurope, Brussels

Boustead I (2005b) Eco-profiles of the European plastics industry: polyurethane rigid foam. PlasticsEurope, Brussels

Boustead I (2006) Eco-profiles of the European plastics industry: polystyrene (Expandable)(EPS). PlasticsEurope, Brussels

British Standards Institution (2011) PAS2050:2011. BSI, London

De Monte M, Padoano E, Pozzetto D (2005) Alternative coffee packaging: an analysis from a life cycle point of view. J Food Eng 66(4): 405-411

Dimenna R (2008) Life cycle inventories for flexible packaging lamination. Retrieved September 12, 2012, from http://www.accredopackaging. $\mathrm{com} /$ and http://www.accredopackaging.com/AdhesivesPELCI.PDF

Eco-costs for Carboxymethyl Cellulose (2012) Retrieved September 26, 2012, from Design-4-Sustainability.com: http://www.design-4sustainability.com/ecocosts/47841

Ekvall T, Tillman A-M (1997) Open-loop recycling: criteria for allocation procedures. Int J Life Cycle Assess 2(3):155-162

European Commission (2007) Integrated pollution prevention and control reference document on best available techniques for the manufacture of large volume inorganic chemicals - solids and others. European Commission, Seville

FedEx (2012) Environment and efficiency metrics. Retrieved October 3, 2012, from FedEx.com: http://about.van.fedex.com/environmentefficiency-metrics\#2

Franklin Associates (2004) Life cycle inventory of packaging options for shipment of retail mail-order soft goods. Retrieved September 26, 2012, from the State of Oregon: http://www.deq.state.or.us/lq/pubs/ docs/sw/packaging/LifeCycleInventory.pdf

Franklin Associates (2009) Life cycle assessment of drinking water systems: bottled water, tap water, and home office delivery water. Retrieved September 28, 2012, from The State of Oregon: http://www.deq.state. or.us/lq/pubs/docs/sw/LifeCycleAssessmentDrinkingWaterFullReport. pdf

Franklin Associates (2011) Cradle-to-gate life cycle inventory of nine plastic resins and four polyeurethane precursors. Retrieved August 2012, from the State of Oregon: http://plastics.americanchemistry. com
IMA-Europe (2007) Retrieved September 19, 2012, from IMA-Europe: http://www.ima-europe.eu/fileadmin/downloads/sustainable/LCA project/LCI_Dry_silica_sand.xls

IMEP (2008) Reducing air pollution from power stations. Retrieved September 12, 2012, from Isreali Ministry of Environmental Protection: http://old.sviva.gov.il/bin/en.jsp?enPage $=$ e BlankPage\&enDisplay=view\&enDispWhat $=$ Object\&enDispWho $=$ Articals ${ }^{\wedge} 12033 \&$ enZone $=$ Electricity Production

International Institute of Refrigeration (2002) Industry as a partner for sustainable development. The Beacon Press, Uckfield

ISO (2006) 14040/44 Life cycle assessment. International Organization for Standardization, Geneva

National Institute of Health (2012) Advanced search. Retrieved October 17, 2012, from ClinicalTrials.gov: http://www.clinicaltrials.gov/ct2/ results?term $=$ pharmaceutical $\&$ intr $=$ drug $\&$ fund $=2 \&$ state $1=\mathrm{NA} \%$ $3 \mathrm{AUS} \% 3 \mathrm{ASD}$

NREL (2012) Retrieved 8 2012, from U.S. Life-Cycle Inventory Database: http://www.lcacommons.gov/nrel

PE Americas (2009) Life cycle assessment of U.S. industry-average corrugated product. Retrieved August 2012 from the Corrugated Packaging Alliance: http://www.corrugated.com

Plastics Europe (2008) Environmental product declarations of the European plastics industry: linear low density polyethylene (LLDPE). PlasticsEurope, Brussels

Plastics Europe (2010) Environmental product declarations of the European plastics manufacturers: polyethylene terephthalate (PET) (bottle grade). Plastics Europe, Brussels

Solomon S, Qin D, Manning M, Chen Z, Marquis M, Averyt KB et al (2007) Climate Change 2007: the physical science basis: Contribution of working group I to the fourth assessment report of the IPCC. Cambridge University Press, New York

Summerscales J (2006) Quality Management and Safety Engineering (BSc)-MST 326. Retrieved August 31, 2012, from Plymouth University: http://www.tech.plym.ac.uk/sme/mst324/MST324-05\% 20Azapagic.htm\#AP

Tufvesson L, Börjesson P (2008) Wax production from renewable feedstock using biocatalysts instead of fossil feedstock and conventional methods. Int J Life Cycle Assess 13(4):328-338

UPS (2012) Corporate sustainability report. Retrieved October 3, 2012, from UPS.com: http://responsibility.ups.com/community/Static\% 20Files/sustainability/2011_UPS_CSR_Report.pdf

US Census Bureau (2010) Sate \& county quickfacts. Retrieved October 2012, from US Census Bureau: http://quickfacts.census.gov/

US Environmental Protection Agency (2012a) Carrier performance rankings. Retrieved October 15, 2012, from EPA: http://www.epa.gov/ smartway/documents/partnership/trucks/raw-public-bin-export.xlsx

US Environmental Protection Agency (2012b) eGRID. Retrieved August 2012, from EPA: http://www.epa.gov/cleanenergy/energyresources/egrid/index.html

US Environmental Protection Agency (2012c) User guide for MOVES 2010b. US EPA. Retrieved August 2012, from EPA: http://www. epa.gov/otaq/models/moves/420b09041.pdf 